\title{
Study the Extent of Participation and Empowerment of Farm Women in lac Cultivation
}

\author{
R. Ranjan ${ }^{1}$, S. Shekhar ${ }^{1 *}$, C.V. Singh ${ }^{2}$ and Satish Kumar $^{3}$ \\ ${ }^{1}$ Krishi Vigyan Kendra (ICAR-NRRI), Jainagar, Koderma, Jharkhand-825324, India \\ ${ }^{2}$ Central upland Rice Research Station (ICAR-NRRI, Cuttack), India \\ ${ }^{3}$ GVT- Krishi Vigyan Kendra, Godda, Jharkhand, India \\ *Corresponding author
}

\begin{abstract}
A B S T R A C T
The novel experiments was undertaken among 60 on-campus trainees and 60 off-campus trainees spread among three purposively selected villages under two blocks under the

Keywords

Extent of

Participation,

Empowerment,

Training, Lac

cultivation, Farm

women

Article Info

Accepted:

12 December 2017

Available Online:

10 January 2018

domain of KVK Jainagar, Koderma. The 20 on-campus trainees and 20 off campus trainees were selected randomly from each selected villages. For the purpose of this study, Two variables namely, extent of participation and impact of KVKs in empowering rural women has been operationalized as the degree to which farm women participant in various activities in lac cultivation. The respondents were interviewed personally by a wellstructured interview schedule. The findings on the extent of participation are given under the overall participation and activity wise participation. The salient findings of the study are, majority $(60.80 \%)$ of the respondent had medium level of overall participation, followed by high $(26.60 \%)$ and low $(12.50 \%)$ level of overall participation. Attending group meeting (2.44), operating commercial ventures (2.29) and attending village development work (2.04) are the major activities in lac cultivation, economic activities and social developmental activities, respectively. It was also found that majority of the respondents $(75.00 \%)$ had increased their knowledge level after going through these training courses, $(40.00 \%)$ of the respondents had improved their skill, $(39.10 \%)$ of the respondents became fully independent. The study also revealed that farm women became socially, economically, psychologically empowered and had the power of taking decisions.
\end{abstract}

\section{Introduction}

The Indian council of agriculture research (ICAR), during fifth five Year plan launched an innovative project for imparting vocational training to farmers, farm women, rural youth and field level extension functionaries in the country by establishing Krishi Vigyan Kendera. Women are no longer confined to their homes as house wives. Different efforts are being made by Government and other organizations for the empowerment of rural people in general and rural women in particular. Empowerment does not mean empowering in technical area only but women should remember that they are rational and thinking human beings (Banga, 2010). The contribution of women to national development in the current context and its potential is of greater significance. 
Involvement of Indian women in national women in national progress at all levels is undisputable reality although the degree of involvement varies from time to time and region to region. Women play a significant and crucial role in lac Cultivation because during lean agricultural season they migrate out to other cities for daily wage employment for their needs, and women and children involve in collection and trading activities of the forest produces (Jonko, 2014) which provide some financial help, but merely sufficient for fulfilling the needs of family. Jharkhand is known for the rich forest area including lac hosts.

Jharkhand alone contributed 42 per cent of the nation's production. Lac production was a traditional practice in tribal families dependent on forests and agriculture and, due to its market importance, had potential for substantial incomes. In Jharkhand, about 500,000 families live in the forest regions and are engaged in lac cultivation resulting in the creation of about 35-50 million person-days of employment per year. In this situation lac cultivation may play a vital role for economic strengthening of the rural women. Cultivation of lac is exploited for its products of commerce, viz. resin, dye and wax. It not only provides livelihood to millions of lac growers (Pal, 2009) and earns foreign exchange (Yogi, 2014), but also provide great scope for socioeconomic upliftment of women. Economic upliftment of women is one of the thrust areas in today's social scenario. Despite women's considerable involvement and contribution, their participation in developmental activities has often been underestimated, undervalued and largely ignored. Moreover they are denied of most of the developmental activities. Therefore, the present investigation was designed to study the Extent of Participation and Empowerment of farm women in lac Cultivation especially in koderma district of Jharkhand.

\section{Materials and Methods}

The study was undertaken with an attempt to know the Extent of Participation and Empowerment of farm women in lac Cultivation in koderma district of Jharkhand. The sample group for the present study comprised only the rural women trained through KVK's in two blocks (Jainagar and Markacho) of koderma districts. Two blocks viz., Jainagar and Markacho have been selected based on the availability of more number of specific host plants such as ber (Ziziphus mauritania) and palash (Butea monosperma.) Sample is collected only from those beneficiaries who have undergone training courses. A total sample of 60 oncampus trainees and 60 off-campus trainees spread among three purposively selected villages under two blocks under the domain of KVK Jainagar, Koderma. The 20 on-campus trainees and 20 off campus trainees were selected randomly from each selected villages for data collection.

Thus, in total, there were 120 respondent. A structured interview schedule was framed through which primary data is collected, the rural women are often illiterate and do not respond to questionnaire technique properly, therefore, interview and observation method was used. The structured interview schedules prepared were pre-tested on 10 percent of the respondents to find out any ambiguity and its work ability before final use. The data collected has been carefully scrutinized and condensed into master chart and tabulated in terms of statistical tools to represent in a meaningful way. To get more information regarding the extent of participation and empowerment of farm women in lac Cultivation of rural women both the primary and secondary sources were used. Literature were also collected from journals, annual progress reports symposia/seminar compendium 


\section{Results and Discussion}

\section{Extent of participation of the respondent in lac cultivation}

The extent of participation in this study has been operationalised as the degree to which rural women participation in lac Cultivation.

\section{Overall participation}

The data collected on overall participation of the respondents have been presented in table 1 .

From the table 1, it could be observed that majority $(60.8 \%)$ of the respondents had medium level of participation, followed by high (26.6\%) and low (12.5\%) levels of participation. It could be interpreted that most of the respondent exhibited moderate to high levels of participation. This might be due to the visible and concrete impact of the benefit of lac cultivation. The benefits might include enhanced increase in household income, and socio- economic empowerment as perceived by women members at village level and observed in the locale of research. Among the activities more participation has been observed in social development activities followed by economic developmental activities. This finding is in agreement with the finding of Kumar (2002), Selvarani (2006) and Meenakshi (2011).

\section{Activities - wise participation}

A spectrum of twenty activities with varying degrees of participation in lac cultivation has been administered and relevant data have been collected. The results are presented in the table 2 . The responses were collected on three point continuum as full, occasional and no participation with scores ranging from one to three. Mean scores have been calculated to find that more and the least participation. The activities have been divided into three major components viz., lac cultivation activities, economic developmental activities and social developmental activities.

From the above table 2, mean scores and ranks have been allotted to each activities, attending lac cultivation meetings (2.44) in lac cultivation activities is rank I, operating the commercial venture (2.25) in economic developmental activities is rank I and participation in village developmental works (2.04) in social developmental activities is rank I have been observed in the order of participation. Most of the respondents in the study area are found to be young to middle age categories and had primary education. This might be the reason for majority of respondents who participated regularly in group meeting, formulating plan for the lac cultivation. In respect of social developmental activities most of the members felt delicate to attend gram sabha meeting as they do not vision of importance of it. This might be the reason for low level participation of members in gram sabha meeting. As the group leaders are reported to have motivated the members, more of high levels of participation in social developmental activities has been observed. This finding is in accordance with the finding of Kumar (2002), Selvarani (2006) and Meenakshi (2011).

Table.1 Distribution of respondents according to their Overall participation $(n=120)$

\begin{tabular}{|l|l|l|l|}
\hline Sl. No. & Category & Number & Percrntage \\
\hline 1. & Low & 15 & 12.5 \\
2. & Medium & 73 & 60.8 \\
3. & High & 32 & 26.6 \\
\hline
\end{tabular}


Table.2 Distribution of the respondents based on activity- wise participation ( $\mathrm{N}-120)$

\begin{tabular}{|c|c|c|c|}
\hline Sl. No. & Activities & Mean scores & Rank \\
\hline A. & Lac cultivation activities & & \\
\hline 1. & Attending lac cultivation meetings & 2.44 & I \\
\hline 2. & Formulation plans for the development for the lac cultivation & 2.37 & II \\
\hline 3. & Organizing training & 1.25 & VIII \\
\hline 4 & Sharing the experiences of training undergone & 1.23 & IX \\
\hline 5. & Imparting skills to other members & 1.21 & $\mathrm{X}$ \\
\hline 6. & Organising exposure visits & 1.50 & VI \\
\hline 7. & Reviewing the progress made & 0.78 & XII \\
\hline 8. & Conflict resolution & 1.74 & IV \\
\hline 9. & Assisting for getting loans & 1.71 & V \\
\hline 10. & Interacting with governments official & 0.98 & $\mathrm{XI}$ \\
\hline 11. & Participation in taking group decisions & 1.92 & III \\
\hline 12. & Formulation the rules and regulations for the lac cultivation & 1.46 & VII \\
\hline B. & Economic developmental activities & & \\
\hline 13. & Operating the commercial venture & 2.25 & 1 \\
\hline 14. & Arranging to get resources from supporting institutions & 1.11 & $\mathrm{~V}$ \\
\hline 15. & $\begin{array}{l}\text { Purchasing raw materials for their commercial venture/ } \\
\text { entrepreneurial activity }\end{array}$ & 2.08 & III \\
\hline 16. & Marketing of products & 2.15 & II \\
\hline 17. & $\begin{array}{l}\text { Participation in the lac product exhibitions conducted by } \\
\text { government/ DRDA }\end{array}$ & 2.06 & IV \\
\hline C. & Social developmental activities & & \\
\hline 18. & Participation in village developmenta works & 2.04 & I \\
\hline 19. & Attending gram sabha meeting & 1.34 & III \\
\hline 20. & Attending social action programmes & 2.02 & II \\
\hline
\end{tabular}

Table.3 Knowledge before and after training (N-120)

\begin{tabular}{|c|c|c|c|c|}
\hline Knowledge of Respondents & Before training & $\%$ & After training & $\%$ \\
\hline No-Knowledge (low) & 112 & 93.33 & 03 & 2.50 \\
\hline Partial-Knowledge (Medium) & 08 & 06.66 & 27 & 22.50 \\
\hline Complete (High) & 00 & 00 & 90 & 75.00 \\
\hline$\chi 2=674.892$, P-value $<0.01$ & & & & \\
\hline
\end{tabular}

Table.4 Dependency of respondents after adoption (N-120)

\begin{tabular}{|l|l|l|}
\hline Dependency has & No. of respondents & $\%$ age \\
\hline No change (low) & 19 & 15.83 \\
Reduced (Medium) & 54 & 45.00 \\
Ended (high) & 47 & 39.10 \\
\hline$\chi^{2}=\mathbf{3 8 . 0 0 5}$, P-value $<0.01$ & & \\
\hline
\end{tabular}


Knowledge and skill before and after training

Table 3 presented the distribution of data as per the knowledge of respondents regarding trainings before and after the training. Majority of the respondent $(93.33 \%)$ were having low knowledge, 06.66 per cent respondents were having medium and no one were having high level of knowledge before training, whereas, majority $(75.00 \%)$ of the respondents were having high level of knowledge after training, 22.50 per cent were having medium level of knowledge and meager number of respondents $(2.50 \%)$ were having low level of knowledge after training. The findings of the study revealed that majority of the respondents 75.00 per cent gained high knowledge level after attending the trainings given by Krishi Vigyan Kendras. Thus positive impact of recommended techniques was found among the respondents.

The perusal of the table 4 revealed that after adoption of the recommendation of various vocational trainings given by Krishi Vigyan Kendras, majority of the respondents $(45.00 \%)$ became independent, $(39.10 \%)$ respondents had reduced their dependency and a small number of respondents (15.83\%) did not feel any change in their dependency. Thus majority of the respondents had increased their socioeconomic status after adoption and were fully independent.

Study shows that most of the respondents exhibited moderate to high levels of participation. This might be due to the visible and concrete impact of the benefit of being a member of lac cultivation. The benefits might include enhanced increase in household income, and socio- economic empowerment as perceived by women members at village levels and observed in the locale of research. Among the activities more participation has been observed in social developmental activities followed by economic developmental activities. Hence it can be concluded that vocational tanning course plays a positive role for the empowerment of rural women. Majority of the rural women developed their socio economy status, developed their psychological confidence and became able to take decisions.

\section{References}

Banga, N. 2010. True meaning of empowerment, women and society, 16: 2- 15.

Jonko, B. 2014. The social dynamics of economic empowerment of the tribal community of Jharkhand, Proc. of the Intl. Conf. on Advances In Economics, Management and Social Study-EMS 2014, 51-55. doi: 10.15224/ 978-1-63248-007-1-77.

Kumar K.G. 2002. A study on farm women participation in the TANWA self helps groups. Unpub. M.Sc. (Ag.) Thesis, AC\& RI, TNAU, Coimbatore.

Meenakshi, V. 2011. Participation and empowerment of rural women in self-help groups - an analysis. Unpub. M.Sc. (Ag.) Thesis, AC\& RI, TNAU, Coimbatore.

Pal, G., Bhagat, M. L. and Bhattacharya, A. 2009. Economic and resource use efficiency of lac cultivation in Jharkhand, Indian Journal of Forestry, 32(1): 95-98.

Selvarani, G. 2006. A study on functioning and role of self-help groups towards scio economic empowerment. Unpub. M.Sc. (Ag.)Thesis, AC \& RI, TNAU, Coimbatore

Yogi, R. K., Bhattacharya, A., and Jaiswal A. K., 2014. Lac, plant resins and gums statistics at a glance 2013, ICAR Indian Institute of Natural Resins and Gums, Ranchi (Jharkhand), India, Bulletin (Technical) No. 06/2014, 1-38 pp.

\section{How to cite this article:}

Ranjan, R., S. Shekhar, C.V. Singh and Satish Kumar. 2018. Study the Extent of Participation and Empowerment of Farm Women in lac Cultivation. Int.J.Curr.Microbiol.App.Sci. 7(01): 1343-1347. doi: https://doi.org/10.20546/ijcmas.2018.701.163 